\title{
Design of Portable Mass Spectrometers with Handheld Probes: Aspects of the Sampling and Miniature Pumping Systems
}

\author{
Chien-Hsun Chen, ${ }^{1}$ Tsung-Chi Chen, ${ }^{1}$ Xiaoyu Zhou, ${ }^{1}$ Robert Kline-Schoder, ${ }^{2}$ \\ Paul Sorensen, ${ }^{2}$ R. Graham Cooks, ${ }^{3}$ Zheng Ouyang ${ }^{1}$ \\ ${ }^{1}$ Weldon School of Biomedical Engineering, Purdue University, West Lafayette, IN 47907, USA \\ ${ }^{2}$ Creare Inc, Hanover, NH 03755, USA \\ ${ }^{3}$ Department of Chemistry, Purdue University, West Lafayette, IN 47907, USA
}

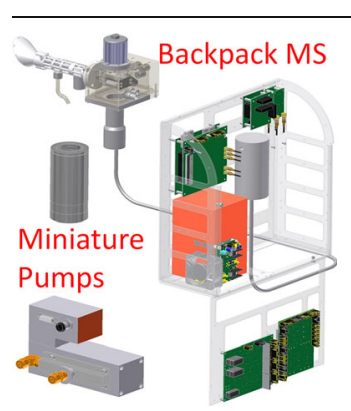

\begin{abstract}
Miniature mass spectrometry analytical systems of backpack configuration fitted with sampling probes could potentially be of significant interest for in-field, realtime chemical analysis. In this study, various configurations were explored in which a long narrow tube was used to connect the turbo and backing pumps used to create and maintain vacuum. Also, for the first time we introduced two new types of pumps for miniature mass spectrometers, the Creare $130 \mathrm{~g}$ drag pump and Creare $350 \mathrm{~g}$ scroll backing pump. These pumps, along with another Creare 550 turbo pump and the commercially available Pfeiffer HiPace 10 turbo and KnF diaphragm backing pumps, were tested with the backpack configurations. The system performance, especially the scan time, was characterized when used with a discontinuous atmo-
\end{abstract} spheric pressure interface (DAPI) for ion introduction. The pumping performance in the pressure region above 1 mtorr is critical for DAPI operation. The $550 \mathrm{~g}$ turbo pump was shown to have a relatively higher pumping speed above $1 \mathrm{mtorr}$ and gave a scan time of $300 \mathrm{~ms}$, almost half the value obtained with the larger, heavier HiPace 10 often used with miniature mass spectrometers. The $350 \mathrm{~g}$ scroll pump was also found to be an improvement over the diaphragm pumps generally used as backing pumps. With a coaxial low temperature plasma ion source, direct analysis of low volatility compounds glass slides was demonstrated, including $1 \mathrm{ng}$ DNP $(2,4-$ Dinitrophenol) and $10 \mathrm{ng}$ TNT (2,4,6-trinitrotoluene) with Creare $550 \mathrm{~g}$ turbo pump as well as $10 \mathrm{ng}$ cocaine and $20 \mathrm{ng}$ DNP with Creare $130 \mathrm{~g}$ drag pump.

Keywords: Ambient Ionization, Discontinuous Atmospheric Pressure Interface, Miniaturization of mass spectrometer, Explosive detection, Backpack mass spectrometer

Received: 26 August 2014/Revised: 30 September 2014/Accepted: 9 October 2014/Published Online: 18 November 2014

\section{Introduction}

$\mathrm{M}$ ass spectrometry (MS) is widely used in chemical and biological analysis typically by collecting samples from the field and analyzing them in the lab. Infield, real-time analysis outside the analytical laboratory is of significant interest for environmental monitoring, [1] forensic analysis [2] at the crime scene, detection of explosives [3,4] and chemical weapons [5] at military and civilian check points, control of pesticide residues for food safety [6], and intra-surgical chemical analysis [7-9] for disease diagnosis. These types of applications

Correspondence to: Zheng Ouyang; e-mail: ouyang@purdue.edu can benefit from the miniaturization of the MS analytical systems, a topic which has been actively pursued using the combination of miniature mass spectrometers and ambient ionization sources [10-13]. Different types of mass spectrometers have been miniaturized, including time-of-flight, [14-16] quadrupole, [17, 18] and ion trap systems [19-24]. The advantages of ion trap analyzers include their small size, relatively high operating pressure and the MS/MS capability. Currently, several portable miniature MS instruments have been developed using ion trap mass analyzers, including as the Mini10, [25] Mini 11, [26] and Mini12 [27] from Purdue University, Tridion-9 GCMS [28] from Torion Inc. (American Fork, UT), GC/QIT [29] from the Jet Propulsion Laboratory, Chemsense 600 [30] from 
Griffin Analytical Technology LLC. (West Lafayette, IN), and the MMS-1000 from 1st Detect Inc. (Austin, TX). To use mass spectrometers outside the analytical laboratory, it is important to have simple analytical procedures that enable complete analysis starting with the samples in their native states. Ambient ionization methods have been developed for this purpose [31-35]. Currently, several ambient ionization methods, including low-temperature plasma (LTP), [11, 36-38] paper spray, [27] and extraction spray, [27] have been demonstrated to provide good analytical performance with miniature ion trap mass spectrometers.

The concept of sampling probes for miniature MS systems has also been explored for ease of operation during real-time analysis in the field. Three different configurations have been investigated for designing a sampling probe with an ambient ionization source (Figure 1). The first approach is to use a long tube (Connection I in Figure 1a) to remotely transfer the desorbed ions from the ambient ionization source to the vacuum manifold containing the mass analyzer. This concept was initially demonstrated with desorption electrospray ionization (DESI) [39] using a long stainless steel tube and later with tubing of larger diameter for pneumatically-assisted ion transfer.[40]. The flow dynamics in the ion transfer process was also studied.[41]. For clinical applications, a rapid evaporative ionization mass spectrometry system (REIMS) system was developed in which tissue was ionized by a surgical knife and the

(a)

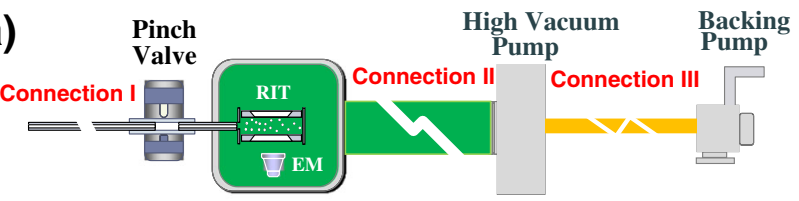

(b)

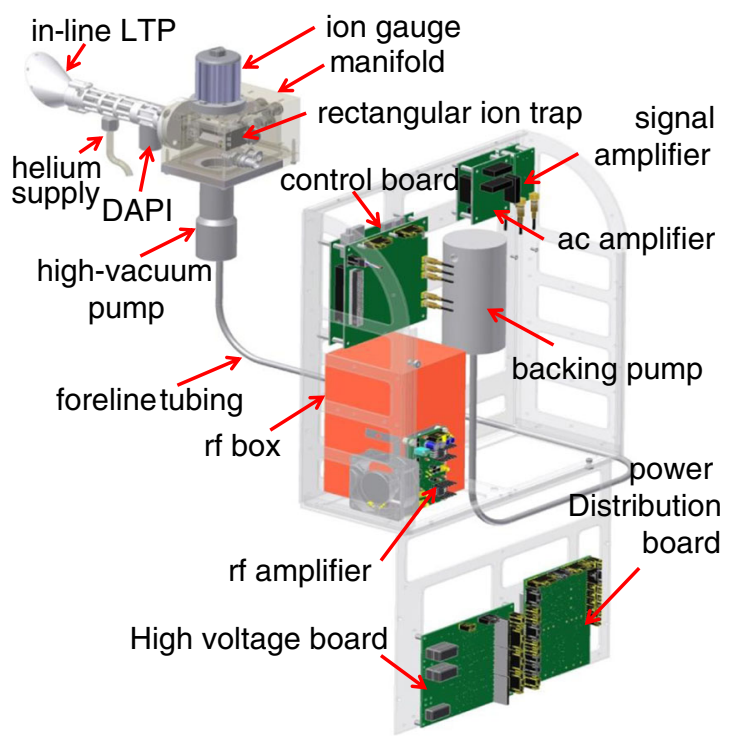

Figure 1. Schematic configurations showing (a) general case for pumping system and a miniature ion trap instrument with a DAPI (pinch valve) and (b) specific case of a backpack MS system with the high-vacuum pump integrated into the handheld sampling unit so that connections I and II can be minimized in length while connection III can be made long ions subsequently transferred to a mass spectrometer for analysis.[7]. A sampling probe using DESI and a narrow $(1.6 \mathrm{~mm}$ i.d.), flexible plastic tube as long as $4 \mathrm{~m}$ was also designed for endoscopic sampling purposes. MS analysis of the remotely transferred ions produced lipid profiles of good quality for tissue sections and intact organs.[42] Transfer of dry ions generated by atmospheric pressure chemical ionization or by LTP over long distances has been shown to have relatively lower efficiency in comparison with transfer of sprayed ions $[41,43,44]$.

The second approach is to keep the sampling/ionization source close to the vacuum manifold containing the mass analyzer, while extending the connection (II in Figure 1a) between the manifold and the high vacuum pump that is packaged together with the backing pump and the control electronics. This concept was first demonstrated using a $1.2 \mathrm{~m}$ long bellows ( $25.4 \mathrm{~mm}$ i.d.) with a modified Mini 10 instrument [45] which practically resulted in a much enlarged manifold volume. A longer time was required for each scan cycle but improved sensitivity was obtained compared to the use of long probes connecting the ionization source to the mass spectrometer. A backpack MS system has recently been developed using this configuration with a coaxial LTP.[13] In this as in all experiments using miniature mass spectrometer, use of the discontinuous atmospheric pressure interface (DAPI) [46] for ion introduction is essential.

The third possible configuration is to integrate the high vacuum pump into the handheld sampling unit while using a long tube (Connection III in Figure 1a) for connection to the backing pump/control electronics package (Figure 1c). The advantage of this configuration is that a much narrower tube (Figure 1b) can be used for this foreline connection, since the pressure inside this tube is about 2 torr and gas flow is pumped by the backing pump [45]. In comparison with the second configuration described above, faster scan speeds can be obtained while using DAPI since no additional gas volume is added on the high vacuum side. This configuration, however, would not be practically applicable unless the high vacuum pump is small enough for integration into the handheld unit, while still providing sufficient pumping. In this study, we used several new prototype miniature pumps developed by Creare Inc. (Hanover, $\mathrm{NH}$ ) to test this third configuration. The performance of several systems with different combinations of high vacuum and rough pumps was characterized.

\section{Experimental}

The handheld unit used has a manifold $(71 \times 74 \times 108 \mathrm{~mm})$ containing a rectilinear ion trap, a channel electron multiplier (DeTech2300, Detector Technology Inc., Palmer, MA) with a conversion dynode, and a DAPI interface. The control electronics of a Mini 11 [26] was used to test MS performance. The flow-constraining stainless steel capillary of the DAPI was $5 \mathrm{~cm}$ long and of $1.5 \mathrm{~mm}$ o.d. and $0.5 \mathrm{~mm}$ i.d. To operate the coaxial LTP probe, [13] an ac voltage of $1,000 \mathrm{~V}$ at $30 \mathrm{kHz}$ was 
used to induce a helium discharge (flow rate $0.2 \mathrm{~L} / \mathrm{min}$ ). 2,4Dinitrophenol (DNP) dissolved in pure methanol solution was used with nanoESI for these test analyses. Methanol solutions of an agrochemical (diphenylamine), an illicit drug (cocaine), and the explosive (TNT, 2,4,6-trinitrotoluene) were prepared and $1 \mu \mathrm{L}$ of each was deposited on a glass slide to form a dried sample spot for LTP analysis. A Pirani gauge (series 925C, MKS Instruments Inc., Andover, MA) was directly mounted onto the vacuum manifold to record pressure. Fans were used to air-cool the prototype pumps during operation.

A flat polished surface surrounding a hole of $30 \mathrm{~mm}$ diameter was made on the vacuum manifold in order to test three high vacuum pumps (Table 1). The Pfeiffer HiPace 10 turbo pump (Pfeiffer Vacuum Inc., Nashua, NH) was connected to the manifold with a connection adapter (DN 25 ISO-KF) and controlled by its integrated electronics with a $24 \mathrm{~V}$ DC power supply. The Creare $550 \mathrm{~g}$ turbo pump was connected directly to the manifold and the supplied DC voltage was increased slowly until its desired rotation speed of $100 \mathrm{k} \mathrm{rpm}$ was achieved. The Creare $130 \mathrm{~g}$ drag pump was directly connected to the manifold and was driven by a microprocessor-controlled drive and control unit (DCU) to achieve $200 \mathrm{k} \mathrm{rpm}$ rotation speed. Two backing pumps, a 2-stage diaphragm pump KnF N84.3 (KNF Neuberger Inc., Trenton, NJ) and a Creare $130 \mathrm{~g}$ scroll pump were tested. The diaphragm pump was driven by a $24 \mathrm{~V} \mathrm{DC}$ power and the scroll pump was controlled by the DCU to achieve $3 \mathrm{k}$ rpm rotation speed.

\section{Results and Discussion}

The pumps used in this study are illustrated in Figure 2 and their specifications are listed in Table 1. Note that the actual pumping speed of a pump changes when the inlet and foreline pressures vary from the specified values. The combination of a HiPace 10 turbo pump and a KnF N84.3 diaphragm pump used for developing the Mini 10[47] has been a popular selection for commercial handheld instruments. The Creare $550 \mathrm{~g}$ turbo pump was used for construction of the $4 \mathrm{~kg}$ Mini 11 system [26]. Both the HiPace 10 turbo pump and the Creare $550 \mathrm{~g}$ turbo pump can provide an ultimate vacuum well below $10^{-5}$ torr. However, for miniature ion trap mass spectrometers with DAPI interface, the working pressure of the manifold is 1 mtorr and this increases up to 1 torr during pulsed gas and ion introduction.[46] Thus, a medium to high vacuum pump with lower compression ratio but a high pumping speed achieved

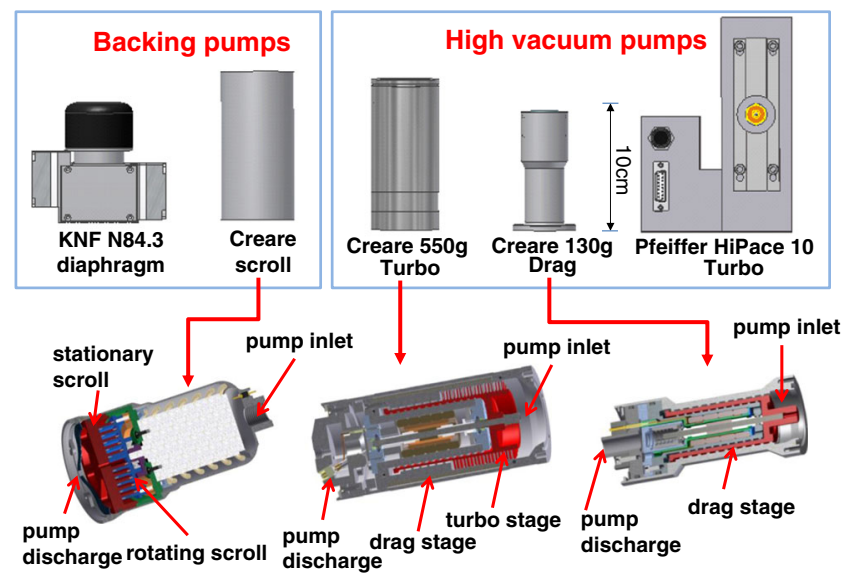

Figure 2. Backing (rough) and high-vacuum pumps used in this study

using only drag stages might be more suitable. To explore this, a Creare $130 \mathrm{~g}$ drag pump with only drag stages was developed. Without the turbo stages, the miniature high vacuum pump could be fabricated at lower cost and potentially might be more robust and allow operation during movement of the instrument. Both the Creare $550 \mathrm{~g}$ turbo and $130 \mathrm{~g}$ drag pumps have form factors that serve better than does the HiPace 10 turbo pump for integration into a handheld unit. A newly developed Creare $350 \mathrm{~g}$ scroll pump was also tested as an alternative backing pump. In comparison with the diaphragm pump, the scroll pump runs extremely quietly, does not vibrate or require maintenance such as replacement of diaphragms, which makes it very attractive for the future development of miniature MS systems.

The feasibility of implementing a long, narrow connection between the high vacuum and backing pumps for miniature instrument was first tested with a Mini 10 fitted with the HiPace 10 turbo pump and KnF N84.3 diaphragm pump. Comparison was made between the original configuration using a $10 \mathrm{~cm}$ tube of $4.8 \mathrm{~mm}$ i.d. (Figure $3 \mathrm{a}$ ) and the new configuration with a $6 \mathrm{~m}$ long tube of the same i.d. (Figure 3b). By using a DAPI opening time of $13 \mathrm{~ms}$ to analyze the ions generated by nanoESI of $5 \mathrm{ppb}$ DNP in methanol, the manifold pressure was raised to 300 mtorr and then pumped down during the closed DAPI cycle. The total time of each scan cycle was set as $600 \mathrm{~ms}$. For the original configuration with the $10 \mathrm{~cm}$ connecting tube, this was sufficiently long to allow the manifold pressure to return to 1 mTorr after the first scan cycle. However, the base pressure increased as the scan cycle was

Table 1. Specifications of backing and high vacuum pumps used in this study

\begin{tabular}{|c|c|c|c|c|c|c|c|}
\hline Pump & Weight (g) & Pumping Speed & $\begin{array}{l}\text { Compression } \\
\text { Ratio }\end{array}$ & $\begin{array}{l}\text { Max. Foreline } \\
\text { Pressure }\end{array}$ & $\begin{array}{l}\text { Max. Power } \\
\text { (W) }\end{array}$ & $\begin{array}{l}\text { Rotor Speed } \\
(\mathrm{rpm})\end{array}$ & $\begin{array}{l}\text { Inlet ID } \\
(\mathrm{mm})\end{array}$ \\
\hline KnF N84.3 Diaphragm Pump & 900 & $5 \mathrm{~L} / \mathrm{min}$ (at $1 \mathrm{~atm}$ ) & & 760 torr & 18 & & \\
\hline Creare 130 g Scroll Pump & 350 & $1 \mathrm{~L} / \mathrm{min}$ (at 1 torr) & & 760 torr & 6 & & \\
\hline HiPace 10 Turbo Pump & 1,800 & $10 \mathrm{~L} / \mathrm{s}$ (at $0.1 \mathrm{mtorr}$ ) & $3 \times 10^{6}$ & 18 torr & 28 & $90 \mathrm{k}$ & 24 \\
\hline Creare 550 g Turbo Pump & 550 & $>4 \mathrm{~L} / \mathrm{s}$ (at $0.1 \mathrm{mtorr})$ & $1 \times 10^{9}$ & 10 torr & 12 & $100 \mathrm{k}$ & 53 \\
\hline Creare 130 g Drag Pump & 130 & $>4 \mathrm{~L} / \mathrm{s}$ (at $0.1 \mathrm{mtorr})$ & $1 \times 10^{5}$ & 10 torr & 12 & $200 \mathrm{k}$ & 25 \\
\hline
\end{tabular}


(a)

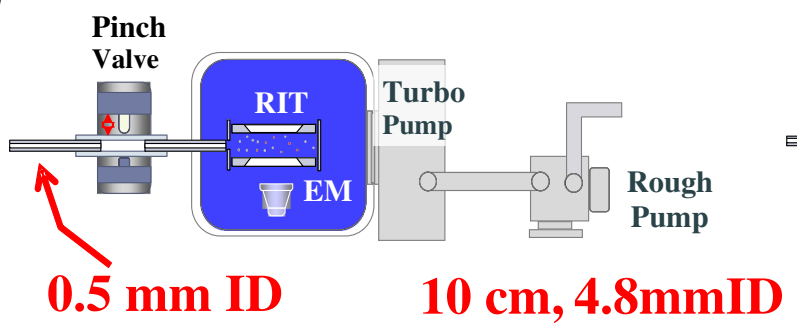

(c)
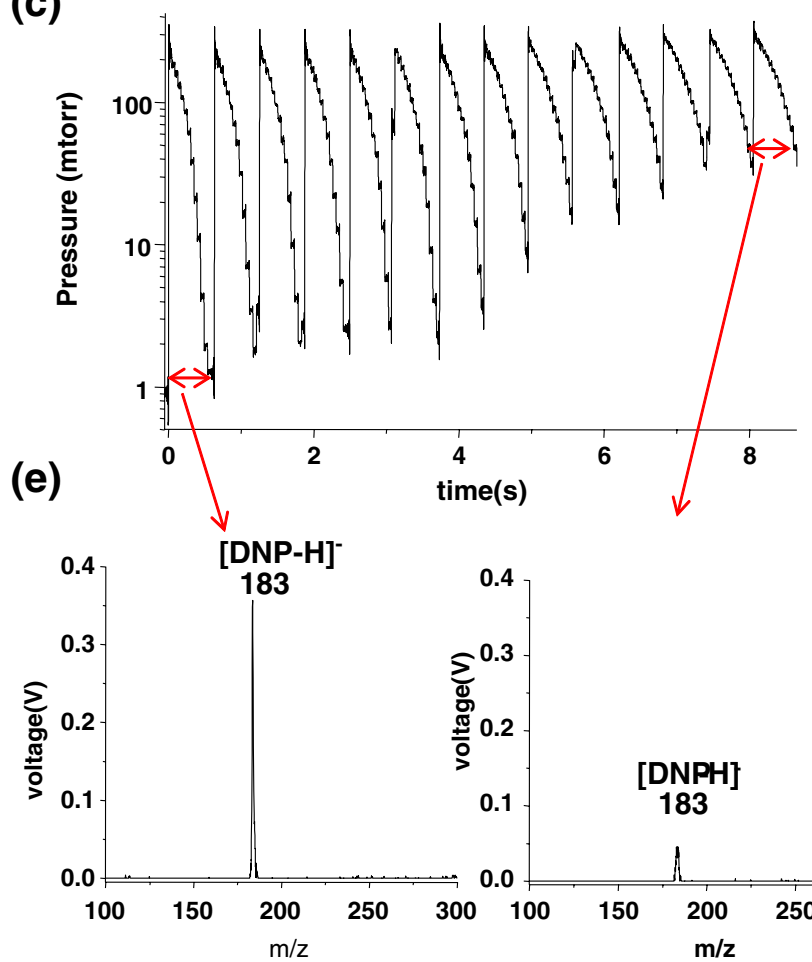

(b)

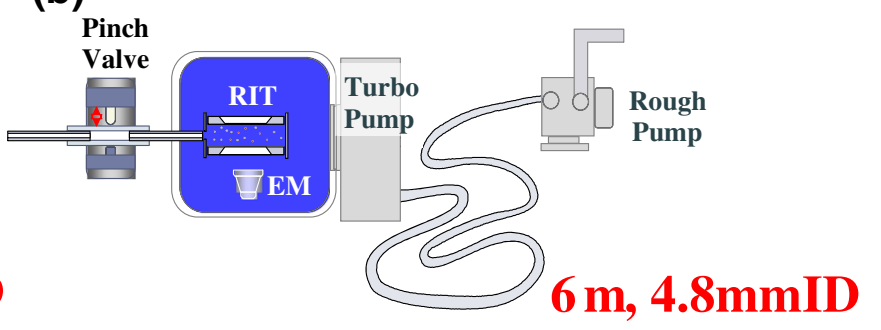

(d)

(f)

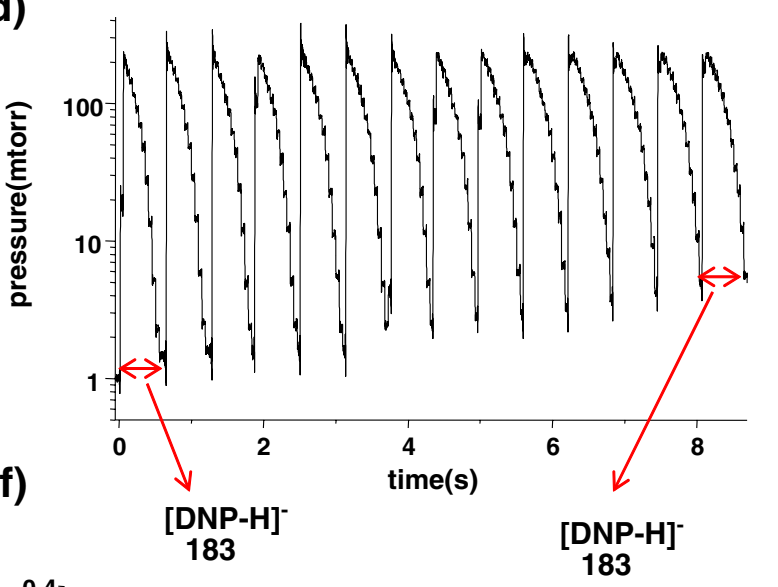

Figure 3. Configurations of miniature MS with (a) $10 \mathrm{~cm}$ long tube and (b) $6 \mathrm{~m}$ long tube as foreline connection between the highvacuum HiPace 10 pump and the diaphragm pump, tube i.d. $4.8 \mathrm{~mm}$. Pressure variations recorded over a number of continuous scans using (c) configuration a and (d) configuration b with $13 \mathrm{~ms}$ DAPI opening, $600 \mathrm{~ms}$ total time for each scan cycle. Spectra recorded with the 1st and 14th scan for (e) configuration a and (f) configuration b, nanoESI of 5 ppb DNP in methanol

repeated and the signal intensity for protonated DNP decreased significantly (Figure 3e), which is likely due to the loss of ions during trapping and less efficient ion ejection during the RF scan at the elevated pressures.[48] This indicates that the delay time between each two adjacent opening events of the DAPI was not long enough to allow the gas introduced to be fully pumped out. Using the same scan time, the base pressure of the manifold and the signal intensity were both better maintained during continuous cycling using the configuration with a $6 \mathrm{~m}$ connection between the high vacuum and rough pumps (Figure $3 \mathrm{~d}$ and $\mathrm{f}$ ).

The differences that were observed over time (Figure 3d) are related to changed foreline pressure in the connection tube, which has an impact on the pumping speed of the turbo as well as the backing pump. With a significantly longer turbo-tobacking connecting tube, the foreline volume was much enlarged and the increase of the foreline pressure due to the introduction of the same amount of gas during a DAPI opening event was thereby much decreased. For validation of this hypothesis, the same test was done with another configuration, in which a $58 \mathrm{~cm}$ long bellow of a larger i.d. of $38 \mathrm{~mm}$ was added in series with the original $10 \mathrm{~cm}$ long, $4.8 \mathrm{~mm}$ i.d. tubing. With this volume of $635 \mathrm{~cm}^{3}$ added into the foreline connection, the base pressure of manifold could be maintained at $1 \mathrm{mtorr}$ with continuous operation at a scan cycle of $600 \mathrm{~ms}$.

Each of the three high vacuum pumps, HiPace10 turbo pump, Creare $550 \mathrm{~g}$ turbo pump and Creare $130 \mathrm{~g}$ drag pump, was then tested with the Creare $350 \mathrm{~g}$ scroll pump using a $1.3 \mathrm{~m}$ long tube of $3.2 \mathrm{~mm}$ i.d. for the foreline connection. A DAPI opening time of $13 \mathrm{~ms}$ was used and the delay time after the DAPI closing was adjusted to find the shortest scan cycle time that allowed a stable base manifold pressure to be maintained for a large number of continuous scans. The results of this characterization are shown in Figure 4. The pressure went up to about 200 mtorr for both the HiPace 10 tubo pump and Creare $550 \mathrm{~g}$ turbo pump (Figure $4 \mathrm{a}$ and $\mathrm{b}$ ). However, the 
(a) HiPace 10
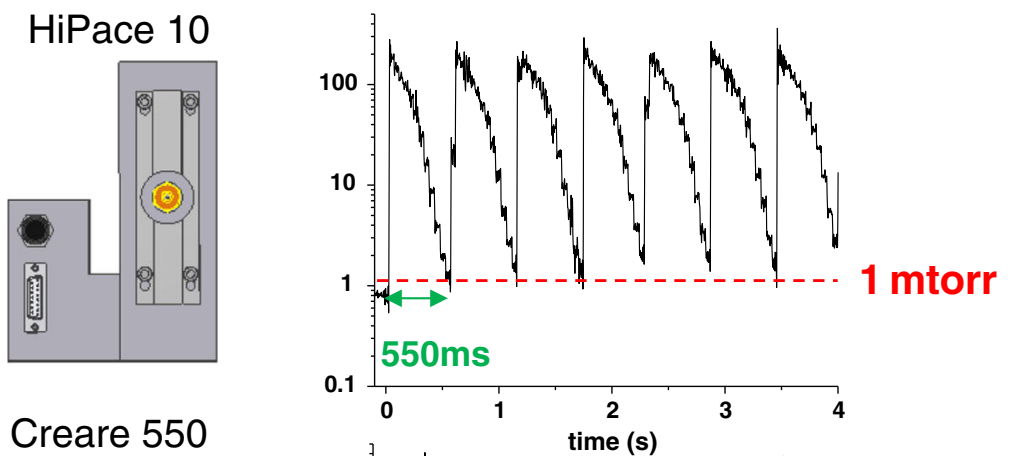

(b) Creare 550

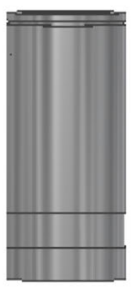

(c) Creare 130
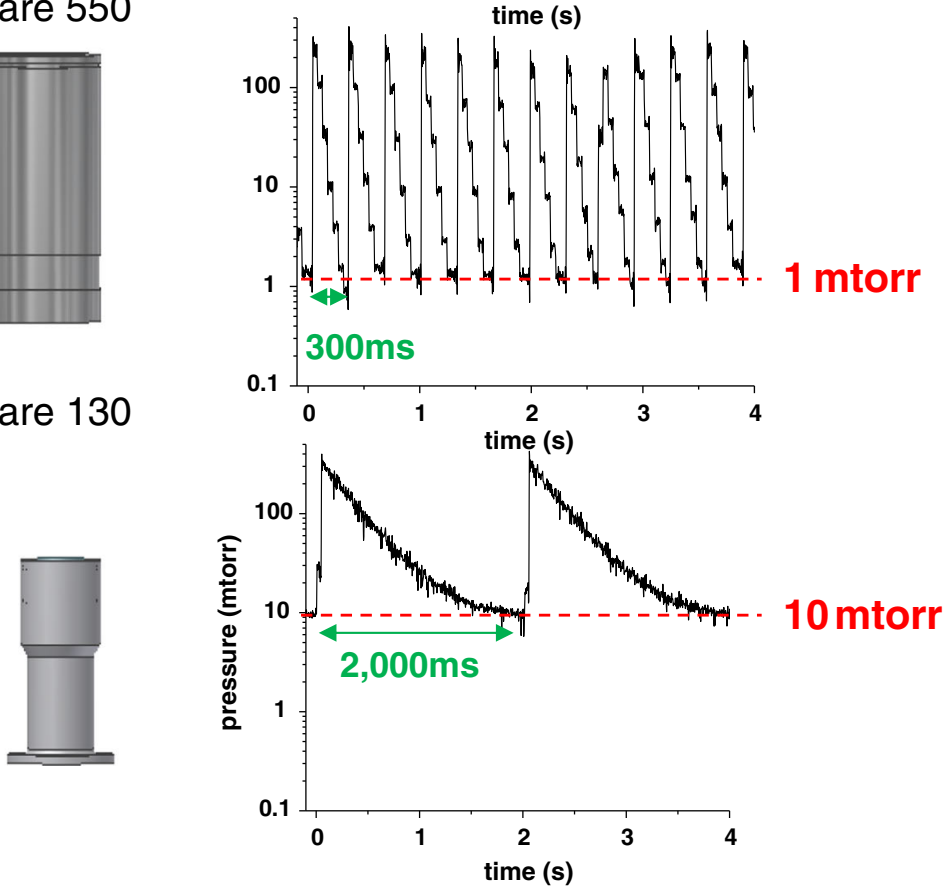

Figure 4. Identification of shortest scan cycle time with sustainable base pressure of manifold during continuous scanning for (a) HiPace 10, (b) Creare 550 and (c) Creare 130, each connected via a $1.3 \mathrm{~m}$ long tube of $3.2 \mathrm{~mm}$ i.d. with the Creare scroll pump

manifold pressure was returned to 1 mtorr faster with the Creare $550 \mathrm{~g}$ turbo pump and a scan time of $300 \mathrm{~ms}$ could be used instead of the $550 \mathrm{~ms}$ for the HiPace 10 turbo pump. Although the HiPace 10 turbo pump has a better specified pumping speed for molecular flow at the ultimate pressure, the Creare 550 turbo pump is the more efficient pump in the higher pressure range above 1 mtorr.

For the smaller Creare 130 drag pump, the manifold pressure rose to about 300 mtorr upon DAPI opening. This could be due to a smaller total volume of the high vacuum region, which affects the pressure buffer as previously discussed [45]. Note that both the manifold size and the pump size contribute to the volume of the high vacuum region. Consistent with this it took a longer time $(2 \mathrm{~s})$ for the pressure to decrease to $10 \mathrm{mtorr}$. The Creare $130 \mathrm{~g}$ drag pump can maintain a vacuum at $10^{-4}$ torr with its inlet sealed directly to the vacuum manifold. When working with the manifold and DAPI of the handheld sampling unit, 10 mtorr was the lowest base pressure it could continuously sustain.

The backpack MS configuration with the extension between the high vacuum and backing pumps was tested with each of the two Creare high vacuum pumps backed by the Creare $350 \mathrm{~g}$ scroll pump. The test involved the direct analysis of low volatility compounds from the glass slides. The coaxial LTP previously developed with the backpack MS was used as the ambient ionization source. Figure 5 shows mass spectra recorded for $1 \mathrm{ng}$ DPA in positive mode and $10 \mathrm{ng}$ TNT in negative mode using the Creare $550 \mathrm{~g}$ turbo pump (Figure $5 \mathrm{a}$ and $\mathrm{b}$ ), and $10 \mathrm{ng}$ cocaine in positive mode and $20 \mathrm{ng}$ DNP in negative mode using the Creare $130 \mathrm{~g}$ drag pump (Figure 5c and d). Although MS analysis was performed at 10 mtorr with Creare 130 g drag pump, good sensitivity and resolution was still obtained. For the case of DNP, a signal-to-noise ratio of about 30 was obtained for detection of $10 \mathrm{ng}$ DNP (Figure 5d) and the limit of detection (LOD) is estimated to be $2 \mathrm{ng}$. The resolution was 0.7 (FWHM, full width at half maximum) when MS analysis was performed at 1 mtorr using the HiPace 10 turbo pump or with the Creare $550 \mathrm{~g}$ turbo pump. The peak widths dropped to 1.8 (FWHM) when operating at 10 mtorr using the Creare $130 \mathrm{~g}$ drag pump. MS/MS was performed for structural confirmation (insets in Figure 5c and d) and the slight loss 


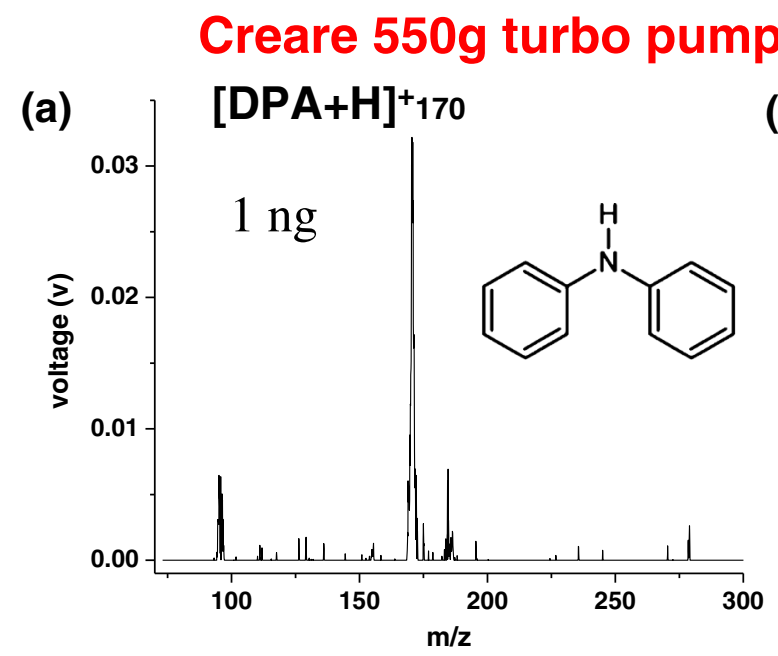

\section{+ Creare $350 \mathrm{~g}$ scroll pump}
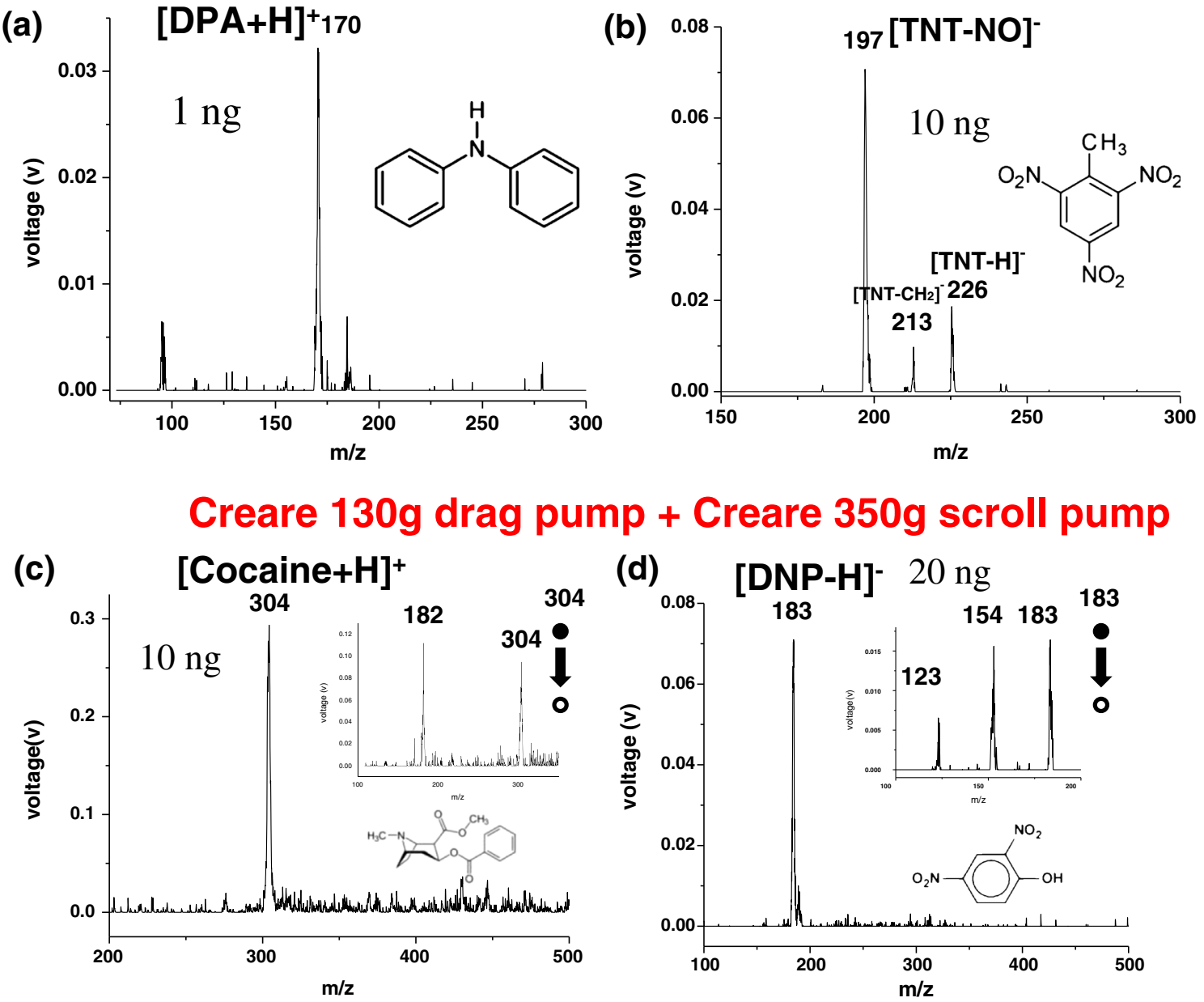

$\mathrm{p}+$ Creare $350 \mathrm{~g}$ scroll pump

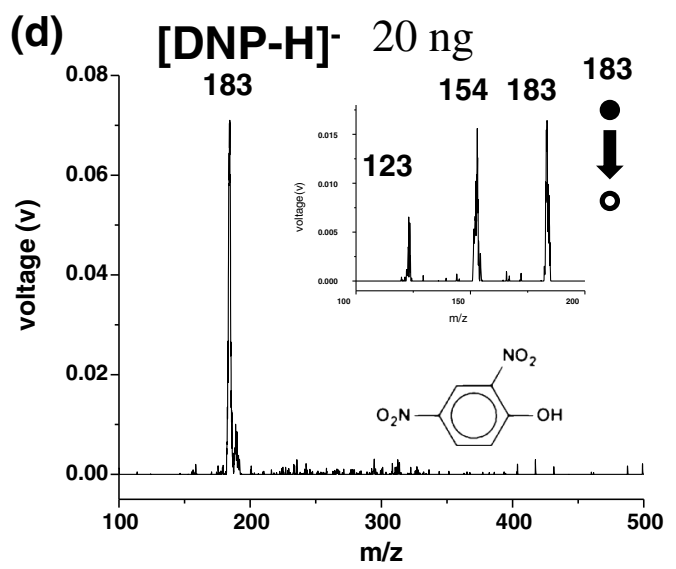

Figure 5. Mass spectra recorded using a handheld sampling unit with a coaxial LTP ion source for direct analysis of chemicals from glass slides, (a) 1 ng DNP and (b) 10 ng TNT (negative) with Creare 550 turbo pump; (c) 10 ng cocaine (positive) and (d) 20 ng DNP (negative) with Creare 130 drag pump. Both high vacuum pumps were connected via a1.3 m long tube of $3.2 \mathrm{~mm}$ i.d. with the Creare scroll pump

in mass resolution due to the operation at higher pressures might not affect the chemical identification.

\section{Conclusions}

In this study, we introduced new types of small pumps for development of miniature mass spectrometers and explored a new configuration for designing a backpack MS instrument fitted with a sampling probe and a discontinuous interface for ambient ionization sources. The Creare scroll pump operates quietly, provides adequate pumping, and thereby will likely become an attractive alternative to the 2 -stage diaphragm pump currently used in most of the miniature MS systems. The combination of the Creare $550 \mathrm{~g}$ turbo and Creare $350 \mathrm{~g}$ scroll pumps would provide a best performance for miniature DAPIMS systems. The use of a long, narrow tube to extend the connection between the high-vacuum and back pump was demonstrated to be a feasible solution for designing a sampling probe using DAPI for ion introduction. Implementation with the Creare $130 \mathrm{~g}$ drag pump of small form factor and improved robustness would certainly make this design much more practically applicable. Although the operation pressure and MS resolution for the drag pump are compromised in comparison with the larger Creare $550 \mathrm{~g}$ and Pfeiffer HiPace 10 turbo pumps, comparable sensitivity has been achieved and MS/ MS could be implemented to provide additional confirmation to the chemical identity.

\section{Acknowledgments}

We acknowledge the National Science Foundation (Projects CHE 0847205), the National Institute of General Medical Sciences (1R01GM106016) from the National Institutes of Health, National Aeronautics and Space Administration (PIDDP NNX12AB16G), and the Department of Homeland Security (Project D10PC20035 and D12PC00210) for funding support. 


\section{References}

1. Kibelka, G.P.G., Timothy Short, R., Toler, S.K., Edkins, J.E., Byrne, R.H.: Field-Deployed Underwater Mass Spectrometers for Investigations of Transient Chemical Systems. Talanta 64, 961-969 (2004)

2. Ifa, D.R., Jackson, A.U., Paglia, G., Cooks, R.G.: Forensic Applications of Ambient Ionization Mass Spectrometry. Anal. Bioanal. Chem. 394, 1995-2008 (2009)

3. Justes, D.R., Talaty, N., Cotte-Rodriguez, I. and Cooks, R. G.: Detection of Explosives on Skin Using Ambient Ionization Mass Spectrometry. Chem. Commun. 2142-2144 (2007)

4. Takats, Z., Cotte-Rodriguez, I., Talaty, N., Chen, H.W. and Cooks, R.G.: Direct, Trace Level Detection of Explosives on Ambient Surfaces by Desorption Electrospray Ionization Mass Spectrometry. Chem. Commun. 1950-1952 (2005)

5. Nilles, J.M., Connell, T.R., Durst, H.D.: Quantitation of Chemical Warfare Agents Using the Direct Analysis in Real Time (Dart) Technique. Anal. Chem. 81, 6744-6749 (2009)

6. Garcia-Reyes, J.F., Jackson, A.U., Molina-Diaz, A., Cooks, R.G.: Desorption Electrospray Ionization Mass Spectrometry for Trace Analysis of Agrochemicals in Food. Anal. Chem. 81, 820-829 (2009)

7. Balog, J., Sasi-Szabo, L., Kinross, J., Lewis, M.R., Muirhead, L.J., Veselkov, K., Mirnezami, R., Dezso, B., Damjanovich, L., Darzi, A., Nicholson, J.K. and Takats, Z.: Intraoperative Tissue Identification Using Rapid Evaporative Ionization Mass Spectrometry. Sci. Transl. Med. 5, 194ra93 (2013)

8. Calligaris, D., Norton, I., Feldman, D.R., Ide, J.L., Dunn, I.F., Eberlin, L.S., Cooks, R.G., Jolesz, F.A., Golby, A.J., Santagata, S., Agar, N.Y.: Mass Spectrometry Imaging as a Tool for Surgical Decision-Making. J. Mass Spectrom. 48, 1178-1187 (2013)

9. Liu, J.J., Ouyang, Z.: Mass Spectrometry Imaging for Biomedical Applications. Anal. Bioanal. Chem. 405, 5645-5653 (2013)

10. Sanders, N.L., Kothari, S., Huang, G.M., Salazar, G., Cooks, R.G.: Detection of Explosives as Negative Ions Directly from Surfaces Using a Miniature Mass Spectrometer. Anal. Chem. 82, 5313-5316 (2010)

11. Soparawalla, S., Tadjimukhamedov, F.K., Wiley, J.S., Ouyang, Z., Cooks, R.G.: In Situ Analysis of Agrochemical Residues on Fruit Using Ambient Ionization on a Handheld Mass Spectrometer. Analyst 136, 4392-4396 (2011)

12. Mulligan, C.C., Talaty, N. and Cooks, R.G.: Desorption Electrospray Ionization with a Portable Mass Spectrometer: In Situ Analysis of Ambient Surfaces. Chem. Commun. 1709-1711 (2006)

13. Hendricks, P.I., Dalgleish, J.K., Shelley, J.T., Kirleis, M.A., McNicholas, M.T., Li, L.F., Chen, T.C., Chen, C.H., Duncan, J.S., Boudreau, F., Noll, R.J., Denton, J.P., Roach, T.A., Ouyang, Z., Cooks, R.G.: Autonomous in Situ Analysis and Real-Time Chemical Detection Using a Backpack Miniature Mass Spectrometer: Concept, Instrumentation Development, and Performance. Anal. Chem. 86, 2900-2908 (2014)

14. Ecelberger, S.A., Cornish, T.J., Collins, B.F., Lewis, D.L., Bryden, W.A. Suitcase Tof: A Man-Portable Time-of-Flight Mass Spectrometer. Johns Hopkins Apl. Tech. Digest 25, 14-19 (2004)

15. Shimma, S., Nagao, H., Aoki, J., Takahashi, K., Miki, S., Toyoda, M.: Miniaturized High-Resolution Time-of-Flight Mass Spectrometer MultumS Ii with an Infinite Flight Path. Anal. Chem. 82, 8456-8463 (2010)

16. Hou, K.Y., Dong, C., Zhang, N.S., Xu, X.M., Wang, J.D., Yao, L., Chai, Z.P., Li, H.Y.: Development and Performance of a Miniature Vacuum Ultraviolet Ionization/Orthogonal Acceleration Time of Flight Mass Spectrometer. Chin. J. Anal. Chem. 34, 1807-1812 (2006)

17. Malcolm, A., Wright, S., Syms, R.R.A., Dash, N., Schwab, M.A., Finlay, A.: Miniature Mass Spectrometer Systems Based on a Microengineered Quadrupole Filter. Anal. Chem. 82, 1751-1758 (2010)

18. Pau, S., Pai, C.S., Low, Y.L., Moxom, J., Reilly, P.T.A., Whitten, W.B. and Ramsey, J.M.: Microfabricated Quadrupole Ion Trap for Mass Spectrometer Applications. Phys. Rev. Lett. 96, 120801 (2006)

19. Ouyang, Z., Cooks, R.G.: Miniature Mass Spectrometers. Annu. Rev. Anal. Chem. 2, 187-214 (2009)

20. Ouyang, Z., Noll, R.J., Cooks, R.G.: Handheld Miniature Ion Trap Mass Spectrometers. Anal. Chem. 81, 2421-2425 (2009)

21. Patterson, G.E., Guymon, A.J., Riter, L.S., Everly, M., Griep-Raming, J., Laughlin, B.C., Zheng, O.Y., Cooks, R.G.: Miniature Cylindrical Ion Trap Mass Spectrometer. Anal. Chem. 74, 6145-6153 (2002)

22. Chen, W.D., Hou, K.Y., Xiong, X.C., Jiang, Y., Zhao, W.D., Hua, L., Chen, P., Xie, Y.Y., Wang, Z.X., Li, H.Y.: Non-Contact Halogen Lamp
Heating Assisted Ltp Ionization Miniature Rectilinear Ion Trap: A Platform for Rapid, on-Site Explosives Analysis. Analyst 138, 5068-5073 (2013)

23. Zhu, Z.Q., Xiong, C.Q., Xu, G.P., Liu, H., Zhou, X.Y., Chen, R., Peng, W.P., Nie, Z.X.: Characterization of Bioparticles Using a Miniature Cylindrical Ion Trap Mass Spectrometer Operated at Rough Vacuum. Analyst 136, 1305-1309 (2011)

24. Tian, Y., Higgs, J., Li, A., Barney, B. and Austin, D.E.: How Far Can Ion Trap Miniaturization Go? Parameter Scaling and Space-Charge Limits for Very Small Cylindrical Ion Traps. J. Mass Spectrom. 49, 233-240 (2014)

25. Gao, L., Song, Q.Y., Patterson, G.E., Cooks, R.G., Ouyang, Z.: Handheld Rectilinear Ion Trap Mass Spectrometer. Anal. Chem. 78, 5994-6002 (2006)

26. Liang, G., Sugiarto, A., Harper, J.D., Cooks, R.G., Zheng, O.Y.: Design and Characterization of a Multisource Hand-Held Tandem Mass Spectrometer. Anal. Chem. 80, 7198-7205 (2008)

27. Li, L.F., Chen, T.C., Ren, Y., Hendricks, P.I., Cooks, R.G., Ouyang, Z.: Mini 12, Miniature Mass Spectrometer for Clinical and Other ApplicationsIntroduction and Characterization. Anal. Chem. 86, 2909-2916 (2014)

28. Contreras, J., Murray, J., Tolley, S., Oliphant, J., Tolley, H.D., Lammert, S., Lee, E., Later, D., Lee, M.: Hand-Portable Gas Chromatograph-Toroidal Ion Trap Mass Spectrometer (Gc-Tms) for Detection of Hazardous Compounds. J. Am. Soc. Mass Spectrom. 19, 1425-1434 (2008)

29. Shortt, B.J., Darrach, M.R., Holland, P.M., Chutjian, A.: Miniaturized System of a Gas Chromatograph Coupled with a Paul Ion Trap Mass Spectrometer. J. Mass Spectrom. 40, 36-42 (2005)

30. Smith, J.N., Noll, R.J., Cooks, R.G.: Facility Monitoring of Chemical Warfare Agent Simulants in Air Using an Automated, Field-Deployable, Miniature Mass Spectrometer. Rapid Commun. Mass Spectrom. 25, 1437-1444 (2011)

31. Cooks, R.G., Ouyang, Z., Takats, Z., Wiseman, J.M.: Ambient Mass Spectrometry. Science 311, 1566-1570 (2006)

32. Harris, G.A., Galhena, A.S., Fernandez, F.M.: Ambient Sampling/ Ionization Mass Spectrometry: Applications and Current Trends. Anal. Chem. 83, 4508-4538 (2011)

33. Weston, D.J.: Ambient Ionization Mass Spectrometry: Current Understanding of Mechanistic Theory; Analytical Performance and Application Areas. Analyst 135, 661-668 (2010)

34. Harris, G.A., Nyadong, L., Fernandez, F.M.: Recent Developments in Ambient Ionization Techniques for Analytical Mass Spectrometry. Analyst 133, 1297-1301 (2008)

35. Huang, M.Z., Yuan, C.H., Cheng, S.C., Cho, Y.T., Shiea, J.: Ambient Ionization Mass Spectrometry. Annu. Rev. Anal. Chem. 3(3), 43-65 (2010)

36. Garcia-Reyes, J.F., Harper, J.D., Salazar, G.A., Charipar, N.A., Ouyang, Z., Cooks, R.G.: Detection of Explosives and Related Compounds by LowTemperature Plasma Ambient Ionization Mass Spectrometry. Anal. Chem. 83, 1084-1092 (2011)

37. Wiley, J.S., Shelley, J.T., Cooks, R.G.: Handheld Low-Temperature Plasma Probe for Portable "Point-and-Shoot" Ambient Ionization Mass Spectrometry. Anal. Chem. 85, 6545-6552 (2013)

38. Dalgleish, J.K., Hou, K.Y., Ouyang, Z., Cooks, R.G.: In Situ Explosive Detection Using a Miniature Plasma Ion Source and a Portable Mass Spectrometer. Anal. Lett. 45, 1440-1446 (2012)

39. Cotte-Rodriguez, I., Mulligan, C.C., Cooks, G.: Non-Proximate Detection of Small and Large Molecules by Desorption Electrospray Ionization and Desorption Atmospheric Pressure Chemical Ionization Mass Spectrometry: Instrumentation and Applications in Forensics, Chemistry, and Biology. Anal. Chem. 79, 7069-7077 (2007)

40. He, J.M., Tang, F., Luo, Z.G., Chen, Y., Xu, J., Zhang, R.P., Wang, X.H., Abliz, Z.: Air Flow Assisted Ionization for Remote Sampling of Ambient Mass Spectrometry and Its Application. Rapid Commun. Mass Spectrom. 25, 843-850 (2011)

41. Garimella, S., Xu, W., Huang, G.M., Harper, J.D., Cooks, R.G., Ouyang, Z.: Gas-Flow Assisted Ion Transfer for Mass Spectrometry. J. Mass Spectrom. 47, 201-207 (2012)

42. Chen, C.H., Lin, Z.Q., Garimella, S., Zheng, L.X., Shi, R.Y., Cooks, R.G., Ouyang, Z.: Development of a Mass Spectrometry Sampling Probe for Chemical Analysis in Surgical and Endoscopic Procedures. Anal. Chem. 85, 11843-11850 (2013)

43. Chen, T.C., Xu, W., Garimella, S., Ouyang, Z.: Study of the Efficiency for Ion Transfer through Bent Capillaries. J. Mass Spectrom. 47, 1466-1472 (2012)

44. Lin, B.W., Sunner, J.: Ion-Transport by Viscous-Gas Flow-through Capillaries. J. Am. Soc. Mass Spectrom. 5, 873-885 (1994) 
45. Hou, K.Y., Xu, W., Xu, J.A., Cooks, R.G., Ouyang, Z.: Sampling Wand for an Ion Trap Mass Spectrometer. Anal. Chem. 83, 18571861 (2011)

46. Gao, L., Cooks, R.G., Ouyang, Z.: Breaking the Pumping Speed Barrier in Mass Spectrometry: Discontinuous Atmospheric Pressure Interface. Anal. Chem. 80, 4026-4032 (2008)
47. Keil, A., Talaty, N., Janfelt, C., Noll, R.J., Gao, L., Ouyang, Z., Cooks, R.G.: Ambient Mass Spectrometry with a Handheld Mass Spectrometer at High Pressure. Anal. Chem. 79, 7734-7739 (2007)

48. Xu, W., Song, Q.Y., Smith, S.A., Chappell, W.J., Ouyang, Z.: Ion Trap Mass Analysis at High Pressure: A Theoretical View. J. Am. Soc. Mass Spectrom. 20, 2144-2153 (2009) 